sonal experience and searching literature, as many parallel cases as possible are summoned as witnesses; then the mathematical theory of chances and probabilities is brought to bear and the conclusion is reached. It seems strange, at first sight, that in art so varied as medicine, mathematics should have any possible bearing, and yet in the almost parallel science of life insurance, mathematics has found one of its most useful applications. The life insurance company can not say with certainty that a certain man of 40 years of age will live so many years, but it can say with very close certainty of a particular group of ten thousand men, that so many will be alive and so many will be dead in ten years. It is the same way with the prognosis of particular classes of disease. If we can assemble, from personal experience and experience as recorded in literature, a group of one hundred of whom ninety have survived a year, we can give a prognosis in the particular case, all attending circumstances being carefully considered, that the chances of survival for a year are nine out of the ten; in the same way is the prognosis of the time of recovery in particular cases. If we have summoned to our aid, truthfully, a group of parallel cases, and have intelligently discounted particular surrounding circumstances, we can give a prognosis as to the time of recovery which will be correct six times out of seven; seven times out of eight; eight times out of nine, or nine times out of ten, according to the breadth of our knowledge, and the accuracy of our observation.

The value of the constant habit of prognosis can not but be very great to the individual physician. It will give him encouragement and hope in many a desperate case, and save him from undue disappointment when the inevitable laws of nature have run their relentless course. He who has mastered the art of prognosis stands, as it were, on the summit of a mountain where hecan see beyond his fellows who have not climbed up the steep and laborious path. Observe the calm philosophy of this man, who with his eye ever on the future, neither urges rash measures nor advocates undue delay, and who is not carried away by the promises of false prophets. $\mathrm{He}_{\mathrm{e}}$ is not deceived by the bright coloring given to the landscape, by the passing meteor, into the belief that the force of all nature has been permanently changed.

The ideal opportunity for the study of therapeutics would be by the treatment of exactly parallel cases by several methods, and their comparison at the same time with cases untreated and pursuing the natural course of the disease. These conditions are only found in rare instances and in large hospitals. Usually, if cases are treated by various methods, it is at different times and the mind pictures of older cases are dim and indistinct. The untreated case is hardly to be found. It is in supplying the place of untreated cases that the development of the habit of prognosis finds its most important place. By careful analysis of the case in hand, by summoning to one's use the records of previous cases accurately observed, by discounting the treatment of one by the treatment of another, and observing the course and outcome under various conditions, one may construct an ideal case similar to the one in hand, but with its history continued into the future. This ideal case supplies a prognosis by which to be guided in the selection of therapeutic measures, the judgment of their efficacy and the expectation as to cure.

Prognosis is often enough modified by the wealth or poverty of the patient, by his character, by his hopefulness or depression, and by a thousand other things that arise in the individual case, but the discussion of more exact methods of prognosis must find a place elsewhere. What would be emphasized is this, that every physician should form the habit of constructing a well-founded judgment as to the future course of any case of which he seriously undertakes the care. With this judgment he should constantly compare the course of this case while under treatment, and honestly acknowlege the futility of useless therapeutics as well as the modifying influence of really valuable measures.

The remark is often made that prognosis is not worth while, that it does not influence the outcome of the case, that a wrong prognosis is apt to bring disrepute, and that it is better to treat the case from day to day, and leave the result with Providence. This is the reasoning of those who take a superficial, and as it were, a symptomatic view of disease; is the reasoning begotten of intellectual laziness, timidity, and selfconceit. How much more moral courage does the physician exhibit, who throwing his whole intellectual acumen into a case, carefully studies all the circumstances, carefully summons to his aid his own experience, and that of others, and then having given the results of his very best work, is willing to stake his reputation on the result. Even from a lower standpoint, that of professional reputation and success, this in the long run pays best. The greatest physicians in all times have made errors, but the con. sultants, the men whose counsel is sought in time of great danger, have been men of strong characteristics, who were able and willing to form an opinion and to stand faithfully by that opinion when formed. The mistakes of such men are apt to be condoned while their successes become a glory to their profession, which obscure practitioners are proud to promulgate.

\section{REPORT ON THE TREATMENT OF PULMO.} NARY TUBERCULOSIS.

Read in the section on Practice of Medicine. at the Forty eighth Annual Meeting of the American Medical Association, held at Philadelphia, Pa., June 1-4.

\section{BY DELANCEY ROCHESTER, M.D.}

ADJUNCT PROFESSOR OF THE PRINCIPLES AND PRACTICE OF MRDICINE MEDICAL DEPARTMENT, UNIVERSITY OF BUFFALO BUFFALO, N. Y.

This report covers in most of the cases a period of about eight months, in some of the cases a period of nearly two years.

The various remedies, upon the use of which the report is made, are Edson's aseptolin, Paquin's tubercle antitoxin and Vaughan's nuclein. In all rases where the stomach does not rebel, cod liver oil was also used. Alcoholic stimulants have not been used, except as temporarily called for. Locally, inhalations, sprays and insufflations consisting of iodoform in ether and in powder, menthol in albolene, essence of peppermint and a mixture of acetanilid, carbolic acid and glycerite of tar according to the formula of Dr. R. P. Lincoln of New York City, have been used. In all cases reported the tubercle bacillus was found in the sputum.

Following is the detailed statement of cases treated by aseptolin (which is a solution containing 3 per cent. of absolute phenol and 0.01 per cent. of pilocarpin-phenyl-hydroxid). This is in no sense an antitoxin but is designed, according to Dr. Edson's 
statement, "to greatly reinforce the natural antiseptic power of the blood."

Case 1.-D. N., male, age 47, nativity United States.

May 4, 1896. Previous history.-Has been running down for nearly a year ; coughing and raising considerable; vomiting frequently ; having irregular chills followed by high fever and night sweats; weight at this date 119 pounds. Tubercular infiltration of right upper lobe; aseptolin treatment begun.

May 21. Since the treatment began patient feels better, appetite has improved, no chills or vomiting, temperature has not gone above $100 \mathrm{~F}$., no night sweats, weight 121 pounds. Pulmonary condition unchanged. Supply of aseptolin gave out and treatment was omitted until June 19 when general and local conditions were not different from previous record. Weight 124 pounds.

July 16. During last month there have occurred two hemoptyses and treatment was omitted for five to seven days each time. The upper lobe of right lung shows distinct sign of softening, and cough and expectoration have greatly increased in amount, but temperature has not gone above 98.5 ; there have been no chills, sweats or vomiting and the weight is 129 pounds.

A ugust 13. No change in patient's condition except that he has lost appetite, feels weak and dispirited and physical exam ination reveals extension of the area of softening. Weight 131 pounds.

August 23. Profuse hemorrhage; weak and discouraged; weight $130^{1}$, pounds.

Oetober 2. Since last record patient has had two more hemorrhages, not so severe. and nore since September 4 ; feels a little stronger and in better spirits. Temperature has reached 100 several times. Pulmonary condition not materially changed. Weight 131 pounds.

October 20. During last three weeks patient has felt worse there has been increase in cough and expectoration and there has been vomiting (caused generally by the iodoform spray). Physical examination reveals infiltration in left upper lobe and distinct eavity in right upper lobe. Weight 129 pounds.

December 1. Patient's general condition has improved somewhat, vomiting has stopped, cough is not so distressing, but temperature has ranged rather above 100 , reaching $101 \mathrm{sev}$ eral times. Physical examination shows steady advance of the tubercular process in both lunge. Weight $1291 / 4$ pounds. Patient complained bitterly of the pain of the injections and treatment was stopped.

Case 2.-H. K., male, aged 37, nativity. United States. Aseptolin.

July 15, 1896. Previous history.-For eighteen month there has been progressively increasing anemia, and malaise, marked anorexia, night sweats and occasional hemoptyses, considerable dyspnea, lack of sleep and depression of spirits. There was consolidation of upper left lobe and some infiltration throughout the rest of the left lung. The temperature frequently reached 101 and sometimes fell as low as 97. The respirations ranged in the neighborhood of 30 and the pulse from 80 to 100 . The weight record of this case for the first three months was lost. Cough was very troublesome, almost continuous, and there was a large amount of sputum raised.

August 13. During the last month there has been great improvement in all respects; appetite better; sleeps well; cough and expectoration decreased; dyspnea continues; no night sweats since July 18 . Temperature has not gone above 99.2 .

September 12. Condition has remained about the same.

October 13. Improvement continues in all respects, except that cough and expectoration have increased and there is evi dence, on physical examination, of infiltration at right apex in addition to that existing in left lung which has not changed. Weight 130 pounds.

November 10. Improvement continues. Weight 1341/ pounds.

December 8. Improvement continues. Weight 138 pounds; cough and sputum diminishing.

January 12, 1897. Continued improvement in all respects.

Weight 142 pounds. Aseptolin stopped on account of pain of injections.

February 2. Not quite so well. Weight 1301 pounds.

Case 3.-F. S., male, age 31, nativity United States. Aseptolin.

May 4, 1896. Previous history.--For six months gradual failure in strength and health, anorexia, anemia, marked cough, profuse expectoration, afternoon fever, profuse night sweats. Tubercular infiltration of upper and middle lobes of

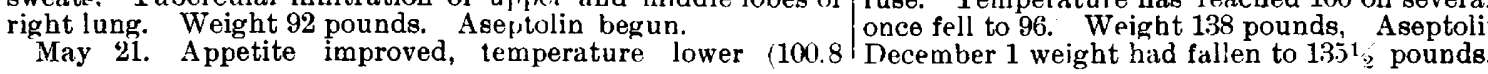
lin omitted until highest), no night sweats. Cough still severe and sputum stil profuse. Marked dyspnea. Weight 92 pounds. Aseptolin omitted until

June 19. During this month improvement continued and cough became less troublesome. Pulmonary condition not changed. Weight 98 pounds.

August 23. During last month there has been falling off of appetite and disappearance of previous sense of improvement Cough and expectoration have again increased and the dyspnea is more marked. There has been an extension of the diseased process downward to the lower lobe of right lung. Weight 100 pounds.

September 2. Aseptolin omitted on account of soreness of abdomen. Temperature has again increased and patient feels weak and dispirited, suffers greatly from dyspnea and complains of pain in left chest. Weight 101 pounds.

October 2. Aseptolin resumed. Patient's general condi tion not materially changed except that soreness in abdominal walls is less. There is evidence of infiltration of entire right lung and of left apex. Weight 98 pounds.

November 8. Patient has gradually and steadily failed in all respects, general and local. There is infiltration of entire right lung and cavity in left upper lobe surrounded by zone of breaking down lung. Weight 91 pounds. Aseptolin stopped. Case 4.-T. D., male, native of Ireland. Aseptolin.

May 2, 1896. Sickness dates back six years. During this time there have been periods of long quiescence with occasional outbursts of cough, fever, etc. These have gradually increased in frequency. Patient is anemic and has no appetite feels very weak, suffers from great dyspnea. There is evi dence of consolidation of upper left lobe, and scattered areas of broncho-pneumonia through rest of left lung and slight bronchitis in upper right. Coughs a great deal with not very much sputum. Temperature not above 100 , pulse 100 , respi ration about 30 , weight 130 pounds.

May 21. During the last three weeks temperature has not gone above 99 , and night sweats have ceased. Otherwise, no change in patient's condition. Weight 128 pounds. A septo-

June 19. During last month no change in patient's condi tion. Weight $126 \frac{1}{2}$ pounds.

July 24. Some general improvement, sleeps well, appetite good, no sweats, cough and expectoration less. Dyspnea marked. Weight 126 pounds.

A ugust 13. General condition not changed. Weight 1221, pounds.

October 13. During last two months there has been no material change in general condition, but the disease in lung has progressed so that there is now cavity in upper left lobe and infiltration in lower left, with bronchitis in right lung. Weight 123 pounds. Aseptolin stopped on account of pain of injection.

December 8. No change in general condition nor in pulmonary condition. Weight 119 pounds.

Case 5.-H. G., male, age 54, nativity United States. Aseptolin.

May 3, 1896. Previous history.-For a year patient has had cough, with slight expectoration, frequent asthmatic attacks, very slight fever occasionally, no night sweats. Has poor appe. tite, is anemic, sleeps poorly, feels weak and debilitated. Has general bronchitis and emphysema and infiltration of right upper lobe and left apex. Temperature ranges from 96.5 to 98.5 , pulse 60 to 90 , and respiration 20 to 30 . Weight 145 pounds. Aseptolin begun.

May 21. No change in condition except that he coughs and raises a great deal now. Weight 149 pounds. Aseptolin omitted until

June 19. No change. Weight 150 pounds.

July 24. During last month sleeps well; appetite not so ood, does not feel as well.

August 23. No change except that cough and expectoration are increasing. Dyspnea somewhat relieved by quebracho. Weight $144 \%$ pounds.

September 1. No change. Weight 146 pounds. Aseptolin topped on account of soreness of abdomen.

October 6. During the last month patient has felt better appetite improved, dyspnea not so marked, but cough and expectoration continue to increase. Weight $1431 \frac{1}{2}$ pounds. Aseptolin resumed

November 17. During last six weeks patient has become worse in all respects. The local conditions have not improved. The cough continues severe and the expectoration very profuse. Temperature has reached 100 on several occasions, and December 1 weight had fallen to 13.51 pounds. 
February 2. Patient has improved in all respects during last two months. Weight $1391 /$ pounds.

Case 6-J. M., male, age 50, English parentage. Aseptolin. August 1. Previous history.-Has had cough and occa sional diarrhea for one year. In December, 1895, had very severe cough. Since then has lost forty pounds in weight, coughs considerable, sputum thick and tenacious and considerable in quantity. Temperature does not go above 100 . During last two weeks has suffered from night sweats. The left apex and the right upper lobe are infiltrated. Weight 150 pounds. Aseptolin begun.

A ugust 23. Pulse stronger, no night sweats, but appetite is poor and he is kept awake by coughing. Has developed slight laryngitis. Weight $1541 \%$ pounds.

September 12. During last three weeks has had some diarrhea; laryngitis has improved. Developed albuminuria with markedly diminished urine. Aseptolin stopped. Weight 152 pounds.

October 9. After the first diminution in the amount of urine secreted, there came a marked increase in amount of urine, and although the albuminuria remained, the polyuria became $\theta x$ treme ; during last two months of his life patient passed from 2000 to 5000 c.c. of urine in twenty-four hours, containing from 20 to $50 \mathrm{gm}$. of urea, though of low sp. gr., and containing albumin in abundance, and some casts. Weight 157 pounds. December 19, he died, having been comatose for twenty-four hours before death. During last two weeks of his life he had two attacks of severe gastritis and developed corneal ulcers in both eyes. His weight two weeks before death was 1361 , pounds. No autopsy.

Case \%.-R. B., male, age 35, nativity United States. Aseptolin.

A ugust 12, 1896. - Previous history.-For six or seven months has suffered from cough and expectoration, chills, fever and night sweats. Loss of appetite, loss of weight, great weakness, marked dyspnea, respirations have ranged between 30 and 40 , pulse 80 to 120 and temperature 97 to 102 degrees. There is infiltration of left apex, infiltration and softening in upper lobe of right lung with bronchitis in middle right lobe. Cough and expectoration slight. Weight 100 pounds. Aseptolin begun. September 12. No material change except that night sweats have ceased and temperature is ranging nearly a degree lower at its maximum, cough and expectoration increasing.

October 13. During last month there has been a steady de. cline in all respects, except that the temperature has ranged lower and the night sweats have not returned. Patient has been troubled greatly with sleeplessness and nightmare. The diseased processes in the lungs have progressed quite rapidly and the cough and expectoration increased in a marked degree. Weight 91 pounds. October 16 , patient died.

In addition to these seven tabulated cases, two other cases were treated with aseptolin although they were rapidly advancing in tubercular destruction of the lungs. In neither case was any bonefit observed from the treatment, either locally or generally. The treatment was stopped after two months. Both cases died. Except in the cases that died the treatment was continued from four to six months. Of the nine cases treated, in seven the night sweats ceased entirely and the temperature range was lower during treatment than before the treatment was begun; in one (case No. 2), there was a gain in weight, and improvement in all general symptoms, appetite increased, sweats ceased, temperature fell to normal or half degree above, but the local conditions as revealed by physical examination did not change though the cough and expectoration were much lessened; in one other (case No. 1), there was gain in weight for four months, sweats ceased, appetite improved, temperature did not range above 100 degrees $F$. but the local changes in the lungs progressed, cough and expectoration increased, there were several hemorrhages and during last two months patient began to lose in weight, appetite failed and temperature began to range higher.

In all of the other cases there was progressive loss in weight, marked progress in the local disease, and no improvement in any symptoms except in the cessation of the night sweats and the somewhat lower range of temperature.
Of the nine cases treated four died, two from two to three months after treatment had been stopped, one during treatment and one, I think, because of the treatment. This case (No. 6), deserves especial men. tion. In this case as in all others, careful examination of the twenty-four hours' excretion of urine was made before treatment was begun. The kidneys were in normal condition. (The urine in all cases was examined every day.) Treatment in this case was begun August 1. On September 12 albuminuria and almost complete suppression of urine occurred. Treatment was immediately stopped. Patient had gained four and one-half pounds during first three weeks of treat. ment and lost two and one-half during last three weeks. During the month following the stopping of treatment he gained five pounds, although the albuminuria persisted and gradually increased. About October 1, three weeks after aseptolin had been stopped, in addition to the albuminuria he developed a marked polyuria which lasted until his death, which occurred December 19. The amount of urine voided daily during the last two months of his life was from 2000 to 5000 c.c., contain. ing from 20 to $50 \mathrm{gm}$. of urea and a large amount of albumin and hyaline, granular and epithelial casts in abundance. During the last two weeks of life he was confined to bed, had three attacks of severe gastritis and developed corneal ulcers in both eyes. $\mathrm{H}_{e}$ died in a state of coma. Autopsy was not secured.

In no case can I report a cure. In judging of the value of aseptolin in these cases we must bear in mind the fact, that the treatment was begun in the early summer and continued through the summer and somewhat into autumn and early winter; that the improvement in those cases in which improvement was noted, took place during the summer, while the weather was such as permitted out-of-door life, but that when the weather grew more inclement and out-of-door life was interfered with, the improvement did not continue. The one thing that impressed me as of value in the use of aseptolin was that in all cases the night sweats were promptly stopped and did not recur. In most cases also, the range of temperature was lowered. As these same results can be obtained by other measures which do not carry with them the possibility of producing an albuminuria and even a nephritis and death, I question whether the use of so dangerous a remedy is justifiable.

The next series of cases I have to report is a series of cases treated with Paquin's tubercle antitoxin.

Case 1.-D. M. was Case 1 of aseptolin series. Aseptolin treatment had been stopped two weeks and patient gained in appetite, ability to sleep, and slightly in weight. Temperature ranged from 98 to 100.5 degrees, pulse 80 to 100 , respiration 20 to 28 . Weight $1301 / 2$ pounds.

December 12, 1896. Tubercle antitoxin begun; there is infil tration in upper left, cavity in upper right.

January 4, 1897. Patient feels very badly, has steadily gone downward since treatment was begun, great pain was produced by the injection; they were followed by a marked dermatitis and by swelling of left axillary glands, headache, gastric pain, anorexia, diarrhea, pain and stiffness in limbs. Temperature ranged during this month from 97 to 102.5 degrees, pulse 80 to 110 , respiration 22 to 28 . Infiltration in upper left remained inactive but there was marked increase in softening about cavity in upper right. Cough and sputum greatly increased. Weight $1291 / 2$ pounds. Treatment stopped.

January 27. Headache and ache in bones have disappeared, sleeps well and feels better. Weight $1261 / 2$ pounds.

Case 2.-F. S. This case had also been an aseptolin (case No. 3), and had not improved since aseptolin stopped.

December 14, 1896, had held his own in weight in spite of three small hemorrhages. Temperature has varied between 98 and 100 , pulse between 88 and 100 , respiration 20 to 24 , cough and 
sputum have diminished, appetite is good, sleeps well, no night sweats, weight $911 / 2$ pounds. Infiltration of left apex and of right upper lobe with bronchitis in right middle lobe. Tubercle antitoxin begun.

January 4,1897 . During the last mon th patient has failed in all to respects; shortly after serum treatment was begun, he began vomiting severely, and has had one severe hemorrhage. Cough and sputum have both increased. Injection set up dermatitis and caused swelling of axillary glands ; the infiltration has proceeded downward from left apex in to entire upper left lobe, softening bas begun in upper right and infiltration has progressed in to middle right. Temperature has ranged from 97 to 101.4 degrees; pulse 80 to 120 , respiration 28 to 40 , weight $88^{3}{ }_{4}$ pounds. Patient is distinctly worse in all respects. Treatment stopped.

Case 3.- T. D. This case also has been on aseptolin (case No. 4), and had not improved. Aseptolin stopped October 13. Since then patient has lost three pounds in wejght but has held his own in other respects. Appetite is fair, sleeps well, feels pretty well, coughs and raises considerable. Temperature 98 to 100 degrees, pulse 70 to 100 , respiration 20 to 30 . There is infiltration in upper left and in middle right, and cavity in upper right. Tubercle antitoxin begun Dec. 14, 1896,

January 5,1897 . During last month patient has lost ground in all points ; feels very badly, appetite gone, sleeps poorly, severe and continuous headache, dermatitis marked, cough and expectoration markedly increased; condition of the left lung remains the same, but there has been marked increase in the softening about cavity in right lung. Temperature 97 to 100 degrees, pulse 80 to 110 , respiration 20 to 30 . Treatment stopped.

February 2. Patient continued to lose weight for three weeks after treatment stopped. Since then has gained a little. Headache ceased : feels, sleeps and eats better. Cough not changed. Case 4.-M. R., male, age 34, native of Ireland. Tubercle antitoxin. Jan. 8, 1897. Previous history.-Negative until in July 1896, when he began to have a slight cough, loss in weight and strength, and suffer from pain in side and chest. Is anemic and has had occasional night sweats. Temperature has ranged from 99 to 101 degrees, pulse 100 to 110 , respiration 20 to 30 , There is infiltration of left upper lobe as far down as the level of the second rib in front, and as far as the spine of the scapula behind. Considerable cough and expectoration. Weight 120 pounds. Antitoxin treatment begun.

February 2. Patient felt better for first two weeks, and gained two pounds in weight which he lost in the third week, but gained one back in next week. The pain in his chest disappeared in first two weeks, but returned with greater severity during last three weeks ; he also developed pain in his left hip and his stomach. During last three weeks has vomited nearly every day, his appetite has failed and the cough and expectoration have increased. His temperature has ranged from 98 to 102 degrees, pulse 90 to 120 , respiration 22 to 34 ; he has had three severe night sweats. Softening has developed in left upper lobe and there has been some extension of disease downward. There has been no dermatitis or swelling of lymph gands. Weight 121 pounds. Treatment stopped.

Case 5.-P. R., male age 54, native of Ireland. Tubercle antitoxin. Previous history: Pneumonia five years ago: cough for two years: hemorrhage one year ago. In September 1896, had another hemorrhage and began to run down in weight and strength. Entered hospital Oct. 14, 1896. Fair appetite, sleep poor, night sweats, occasional diarrhea. Temperature 97.5 to 98.8 degrees, pulse 90 to 100 , respiration 24 to 32 . Cough and expectoration considerable, sputum often blood tinged. Scattered areas of broncho-pneumonia in both lunge, together with considerable emphysema ; cavity in upper right lobe. Weight 12.5 pounds.

December 12, 1896. Under hygienic measures, good diet and creasote, patient has gained nine pounds in weight, hemorrhages have ceased, night sweats less severe and less frequent. Temperature 98 to 98.5 degrees, pulse 90 to 100 , respiration 24 to 30 Areas of broncho-pneumonia have materially diminished, otherwise pulmonary condition is the same. Weight 131 pounds. Tubercle antitoxin begun.

January 4, 1897. From the time injections were begun patient began to feel badly, aching and numbness in limbs and back, headache, bones ache with return of night sweats in great severity, cough and sputum increased greatly in amount and hemorrhages again began. Temperature 97 to 100 degrees, pulse 80 to 120 , respiration 24 to 36 . Areas of broncho-pneu. monia again increased and there developed considerable-poften ing about cavity. Weight 129 pounds. Treatment stopped.

From this time on patient continued to grow worse in all respects; hemorrhages continued, sweats, fever and broncho-pneumonia increased and softening extended; patient finally died March 1, 1897.

I have three other cases treated with tubercle antitoxin to report. One Miss B., age 17, American of German descent. This case I first saw in September, 1896. She at that time was having high fever in the afternoon, night sweats, severe cough, considerable expectoration, poor appetite and occasional diarrhes. She was not weighed. I put her upon Vaughan's 1 per cent. solution of yeast nuclein. She did well upon it, appetite improving, cough diminishing and sweats becoming much less frequent and fever also subsiding to a marked degree. The local condition, which at first showed cavity in right upper lobe, infiltration in rest of right lung and in left upper lobe improved to a considerable degree, the lower lobe of right clearing up almost entirely, the cavity in upper right remaining, but apparently not extending, the infiltration in upper left remaining about the same.

In spite of this improvement I foolishly changed to the antitoxin in December, beginning the injections on December 10. The injections of tubercle antitoxin were very painful, a marked dermatitis occurred and swelling of the axillary lymph nodes. Her general health suffered greatly. The afternoon fever returned, the sweats again became marked, appetite diminished and after about three weeks' treatment the girl declined further treatment by injection of any kind, even declining to go back to the use of nuclein. The local condition took a new start in progress of disease, the cavity on the right side enlarged, the left upper lobe also began to break down and areas of broncho-pneumonia showed themselves in lower lobes of both lungs.

The cases so far reported were undoubtedly cases of mixed infection and it may well be said that good results from a specific antitoxin should not be looked for in such cases. The next two cases were apparently pure tuberculosis. The first, David D., a young man 20 years of age, tubercular family history in grandparent and aunt, consulted me first Dec. 13, 1896 , on account of cough. Physical examination of the chest revealed nothing, but chest tending to pigeon shape and poor development. Examination of throat showed enlarged tonsils, especially the right one, and a reddening of the vocal bands with some edema of false cords. He was referred to a throat specialist who treated the laryngeal condition and a diseased nasal condition without much relief to cough. Patient also began to vomit considerably at this time after severe attacks of coughing. Almost no expectoration, the little that was brought up being mostly glairy mucus not containing tubercule bacilli. On December 31 I amputated the right tonsil. For nearly a week after this the cough was much better. It then began again. His voice became quite hoarse and at times he could only speak in a whisper. Examination of the larynx on Jan. 26, 1897, revealed tubercular infiltration of the laryn $x$ - ulceration of the free margin and superior surfaces of both vocal bands over the anterior halves of the membranous portions-swelling of the arytenoids prevents complete closure of glottis; about this same time physical examination revealed some infiltration of right apex but no softening. Not until a week later were tubercle bacilli found in the sputum, which remained very scanty. On January 26 began injection of Paquin's tubercle antitoxin, and gave them daily for thirty-two days, patient growing stead. ily worse and the injections producing such severe 
pain, lasting for from four to eight hours, that the eased condition in the lungs also progressed so that when put patient dreaded the coming of another day. The upon nuclein,

local condition of the lung did not improve, on the June 11, 1895, her physical condition was poor, her appetite contrary, began to show distinct signs of breaking very small, sleep poor, gastric distress marked, occasiona down. Patient gained three pounds for two weeks tion of the upper right lobe and of the entire left lung with and then lost nearly three. On February 26 the injections were stopped, certainly having done no good and possibly having been productive of harm.

The last case of those treated with tubercule antitoxin was a man from whom a tubercular testicle had been removed two months before. This case presented no evidence of pulmonary tuberculosis, but presented enormously enlarged lymph nodes in the groing and extending into the pelvis and some dis. tance into the abdominal cavity. He was put on the serum injections on Dec. 12, 1<96. He suffered no inconvenience from them and gained in weight and strength. The injections were continued until April 22,1897 , when he left the hospital much improved in general health, apparently not injured by the injec. tions, though at one time they had to be omitted on account of soreness produced, but were begun again in a week. There was, however no change observed in the size or contour of the glands already involved, but on the other hand there was no further extension and involvement of other glands or organs.

The conclusions to which I have come in regard to Paquin's tubercle antitoxin are that in cases of phthisis that are at all advanced it is of no value, and that in the one case of almost pure tuberculosis of larynx and upper lobe in which I used it, it was worse than useless, not having stayed the disease and having produced great physical suffering; that in the case of gland tuberculosis it has apparently done no harm and may yet be of value; that in all cases, with the exception of the last, the pain produced by the injection and the unpleasant after-results in the way of dermatitis and glandular swellings would almost, if indeed not entirely, prohibit its use.

The next series of cases to which I wish to call your attention gives brighter outlook as regards results from treatment.

In 1894 Dr. Victor C. Vaughan of Ann Arbor sent some of the early production of his yeast nuclein to Dr. Chas. G. Stockton of Buffalo, with whom I have the honor to be associated in one of our hospitals. Since that time Dr. Stockton and I have used nuclein on a number of cases of tuberculosis and other infectious diseases. I have yet failed to see a case in which it did not do good. I have seen many in which it has not effected a cure. I have seen some in which it has effected a cure. In all there has been at least temporary improvement.

Case 1. - The case of Miss C. I have already mentioned as showing marked improvement under the 1 per cent. nuclein. She had advanced as far as 3 c.c. at a dose, when, to my great regret, $I$ changed to the tubercle antitoxin and she afterward refused treatment.

Case 2.-Mrs. W. F. H., age 57 ; nativity, United States. Nuclein. Tubercular family history; has coughed more or less for twelve or fifteen years. First came under observation in June, 1894. Suffering with gastric distress after eating; this has troubled her for the last eight years. Case is emaciated and has marked enteroptosis. The study of stomach contents shows slight diminution of hydrochloric acid, impaired motion and impaired absorption, large amount of lactic acid. Infiltration with some softening of upper lobe of left lung. Considerable cough and expectoration in the morning, slight at other time of day. Temperature ranges from 97 to 100 degrees, pulse 100 to 120 , respiration 24 to 30 . She was on cod liver oil, creosote and inhalation of menthol until June 15, 1895. Her weight fell during this year from 111 to 98 pounds. The dis-

softening in the upper lobe. Weight 98 pounds.
August 2,1895 . She felt better and held her own in weight. A small cavity had developed in upper right lobe. The 1 per cent. nuclein was gradually increased in dose until by October, 1895, she was taking 6 c.c. hypodermically daily. She continued at that dose until May 1, 1897, then changed to 5 per cent. solution nuclein, begining with 1.5 c.c. and gradually increasing dose until May 20,1897 , when she was taking 4 c.c. She continued that dose. During these two years she has changed very little in her physical condition, except that the gastric indigestion has been to a great extent overcome. The sleep has improved, the cough has remained about the same, the strength of patient has not increased, the night sweats very seldom occur. Her pulmonary condition has varied, occasionally a little outburst of broncho-pneumonia occurring, but on the whole there has been a slight improvement. Since the beginning of the 5 per cent. nuclein this improvement has become marked.

May 20, 1897, physical examination showed that the cavity in upper right had disappeared though there remained some condensation of tissue there. There was small cavity in upper left with some infiltration about it. The cough diminished, the sputum was about the same in amount but less purulent in character, still containing tubercle bacilli. Temperature 97 to 99 degrees, pulse 100 , respiration 22 to 26 .

Case 3.-Elizabeth McD., age 42, American. Nuclein. First came under observation Nov. 11,1895 . History of pneumonia two years before and pleurisy one year before; since then loss of weight and strength, with cough and considerable expectoration. The records of this case, except the first and last physical examinations, have been lost. The first one, which was made Nov. 11, 1895, when nuclein was begun, showed slight infiltration in upper left, broncho-pneumonia areas in lower right, cavity surrounded by area of softening in upper right. Nuclein, 1 per cent. solution, was begun at 1 c.c. and gradually increased to 4 c.c., in February, 1896. She remained at this dose until she passed from under observation on Aug. 15, 1896, when her general condition was markedly improved; she had gained several pounds in weight, her appetite was good and bowels regular, she slept well, she coughed only occasionally and the last two examinations of sputum (which was very slight in amount) failed to show the presence of tubercle bacilli; physical examination showed that the signs of cavity and softening had entirely disappeared, leaving only the evidence of slight condensation in right apex : the signs of disease in lower right and left lung had entirely disappeared. Pulse 74, temperature 98 degrees, respiration 18.

This case I consider has recovered, though there remains slight condensation in upper right.

Case 4.--John D., age 21, nativity United States. Nuclein. This case came under observation Nov. 14, 1895, with a history of frequently occurring "colds" during the previous two years, and of a severe one in October, 1895, which has remained. Patient is losing in weight, sleeps poorly, has occasional night sweats, becomes slightly cyanosed upon exertion. There is considerable cough and expectoration. There is infiltration in upper right, infiltration and slight sof tening in upper left, bron. chitis in lower left. Temperature 98 to 105 degrees, pulse 85 to 120 , respiration 20 to 34 . Injections of 1 per cent. nuclein begun Nov. 14, 1895. Weight 105 pounds.

December 17, 1895. During last month patient has shown no change in his general condition, except a slight improvement in appetite; the temperature 98 to 102.5 degrees, pulse 72 to 110 , respiration 20 to 30 . Cough and expectoration slightly increased. Area of infiltration and softening in left slightly increased.

January 16, 1896. Nuclein 4 c.c. Slight general improvement during past month, appetite and sleep improved, no night sweits, cough and sputum not materially changed. T'emperature 93 to 101 degrees, pulse 80 to 120 , respiration 20 to 30 . Bronchitis has disappeared from lower left. Area of infiltra tion in upper left has diminished, but there is distinct, though small, cavity in upper left, but evidences of further softening are lacking.

February 17. During last month there has been very marked improvement in general health. Temperature 97 to 99.5 degrees, pulse 76 to 110 , respiration 20 to 26 , cough and sputum diminished, no bronchitis, areas of infiltration in both lungs dimin-
ishing, cavity in left distinctly smaller, no softening about it. 
March 17. Nuclein has reached 6 c.c. Patient's weight has increased to 122 pounds. Temperature 97 to 99 degrees, pulse 70 to 90 , respiration 18 to 22 .

A pril 17. Continued improvement in every respect. Good appetite, sleeps well, normal temperature, pulse and respiration. Improvement in left lung particularly marked. Infiltration in upper right still pronounced. Weight 130 pounds. Patient went to Colorado, but returned in late autumn feeling so well that he has neglected treatment all winter aud spring.

May 20, 1897. Patient feeling very well, appetite good, no fever or sweats. Temperature 98 degrees, pulse 70 to 80 , res. piration 18. Evidences of disease have entirely disappeared from left lung, which seems in normal condition. Slight condensation of upper right with evidence of small cavity poste riorly at junction of suprascapular and interscapular regions. Cough much less, some days none, but sputum still contains the tubercle bacilli.

Case 5. Christina S., age 17, German parentage. Nuclein.

History of measles in early childhood, hip disease when 14 years of age, recurrence of disease at 16 years of age. For four months, during which she was under observation, before nuclein was beyun, she felt badly, was losing in weight, appetite poor, bowels quite irregular, tending to constipation with occasional diarihea.

Physical examination revealed bronchitis in right upper lobe. Infiltration and slight sof tening in left upper especially noticeable anteriorly in the infraclavicular and mammary regions, cough troublesome, expectoration abnut 150 c.c. in twentyfour hours. Pulse 80 to 110 , temperature 97 to 102.5 degrees, respiration 25 to 35 .

September 1, 1896. Nuclein begun. Weight 98 pounds.

September 13. During last two weeks there has been a slight change for better, both in the local signe and in the general symptoms. Pulse 70 to 96 , temperature 97.5 to 98.5 degrees, respiration 24 to 26 .

September 25. During the last ten days an acute pneumonic process has attacked upper left lobe, pulse reaching 120 in fre quency, temperature 104 degrees, respiration 28 to 34

After the subsidence of the pneumonia, the case made steady improvement in all respects; appetite good, bowels regular, color returning to face and patient enjoying a feeling of good health to which she had been a stranger for several years. Her pulse has ranged about 80 , her temperature from 97 to 98.5 degrees, her respiration from 20 to 24 .

May 10, 1897. Her right lung has cleared up entirely, the evidence of softening in the left lung has subsided and there remains only slight condensation in the upper lobe. The sputum has almost entirely gone, not more than 8 c.c. in twenty four hours, containing only six or eight tubercle bacilli, in examination of eight slides, after precipitation of the sputum by means of the centrifuge. Patient has menstruated this week for the first time in a year.

Case 6.-David D., male, age 20, native of United States Nuclein.

This case is the case of laryngeal and upper right lung tuberculosis that was given Paquin's antitoxin from January 29 to Feb. 26, 1897, and did so very poorly. Weight 123 pounds. Temperature 96 to 102.5 degrees, pulse 110 to 120 , respiration 26 to 30 . April $30 \mathrm{I}$ began injections of 5 per cent. nuclein. At this time the patient's condition was one of anemia, anorexia, severe cough, frequent vomiting, poor sleep, great de pression of spirits.

May 20 , 1897.--During last month there has been gradual improvement in all respects; sleeps better, does not vomit so frequently, appetite better, acknowledges (for the first time in four monthsi that he is feeling better. Larynx shows slight improvement, signs of softening in rightlung are disappearing, though condensation remains. Sputum somewhat less in quan tity and a little more easily raised. Pulse ranges from 100 to 110 , temperature 96 to 100 degrees, respiration 24 to 28 .

May 22, 1897. Today noticed the first unpleasant effect from injection of nuclein. Immediately after the injection, which had been gradually increased to 4 c.c., patient said he felt badly, there was great difficulty in breathing and a feeling of nausea followed by a tremendous determination of blood to head and shoulders, giving them a dusky red hue. This lasted about five minutes and then gradually subsided. About one hour later it was followed by a chill which terminated in vomiting, and then the patient felt better but weak. There was left on the shoulders and upper chest a slight purplish mottling. Injection was omitted the following day. For the next four days injections were given, and twice a slight recurrence of the feeling was produced; on the fifth day the attack was similar to but more severe than the first. During the period before the flushing. patient became pulseless, face hecame pinched and drawn and without color, breathing shallow, infrequent and difficult. Death seemed imminent The mottling whieh followed the flushing this time showed itself to be intradermal minute hemorrhages. Two days later I gave a smaller dose with a slight recurrence of the symptoms. The patient was evidently so terrified that the dread of the injection precluded the possible benefit and I have since begun giving the 5 per cent. solution by mouth on an empty stomach, beginning with 2 c.c. and daily and grad ually increasing to 4 c.c., t.i.d.

I should like to mention one other case that has been on treatment for two weeks only, but has made so great improvement as to surprise the patient, all her friends and myself:

Case 1.--Martha McD., aged 24, native of United States, bookkeeper. Nuclein. Came under my observation May 11. Father died of heart disease ; mother of "tumor" ; one sister of consumption.

Patient had measles and whooping cough when 8 to 10 years of age. Began menstruating when 14 years of age. When 18 years old had severe cough lasting two months; has coughed occasionally since. Three weeks ago caught a severe cold by change of clothing. Cough has constantly increased since that time. She has a tubercular aspect and weighs 112 pounds; pulse 104, soft and quick; temperature 99 degrees, respiration 24; she sleeps well and her digestive apparatus is in good condition; heart and blood vessels are sound; blood shows slight anemia. Nose is normal, but there is muco-pus in naso pharynx; larynx normal; particles of broncho-pneumonic infiltration throughout left lung, especially in upper lobe; sputum raised mostly in morning is muco-purulent in character, in chunks, contains tubercle bacilli, streptococe and diplococi lanceolati; amount raised in twenty-four hours 50 to 100 c.c. Treatment: Cod-liver oil and strychnin, t.i.d., and cough mixture of $f$. ext. pruni virg., 1 c.c. ; syr. scillæ comp., 1 c.c. ; syr. lactucarii, 2 c.c.; every two to four hours. Nuclein, 5 per cent. sol., hypodermically ; began with $0.30 \mathrm{gm}$ and increased dose gradually until she is now taking 2 c.c. daily.

May 27. She is feeling well, coughs only in the morning and thinks most of expectoration comes from naso-pharynx. Amount in twenty.four hours 15 c.c., is very tenacious, contains a few diplococci and a few streptococci, no tubercle bacilli. There are, however, still a few rales over upper lobe of left lung.

She has held her own in weight for the last two weeks, whereas before that she had been steadily losing.

Other cases that I have put upon nuclein have not been under observation long enough to justify any report. The following conclusions, however, I think are justified. Nuclein does no harm if injections are not too rapidly increased; the injections are not painful; one case recovered although there was a cavity in the right lung when treatment with nuclein was begun. The chronic case that has been on treatment for two years, receiving a hypodermic dose every day, bears witness to the value of the remedy. Signs of cavity have disappeared from one lung and become much less marked and and more limited in the other; the evidences of softening having also disappeared.

In one case beside the one that recovered, the bacilli have disappeared from sputum, which have become almost none. In another case I have no doubt that recovery might have been reported if the young man would stick to treatment, but he feels so well that he neglects himself, though the bacilli are still present and there remains signs of small cavity.

In closing this report I want to lay great stress upon the importance of properly conducted exercises in the treatment of pulmonary tuberculosis. Exereises designed to develop the chest muscles and increase the lung capacity; specific directions as to the character and amount of exercise and the time of day when the exercise should be taken are necessary. Whatever specific medication we may use, without exercise and fresh air our efforts will come to naught. The treatment of special symptoms deserves a few words: 
Cough.-This symptom is generally best relieved by attention to the upper air passages, keeping them clean and free from secretion and by inhalations, mentha in some of its forms having been, in my experience, productive of the best results. The constant inhalation of essence of peppermint through a perforated zinc mask, as suggested by Carasso of Genoa, is especially valuable. When internal medication is needed to give further relief, the cough being irritating and the sputum difficult to raise, a combination of the fl. ext. pruni virg., syr. scillæ comp. aa 1 c.c., and syr. lactucarii q. s. ad 8 c.c. at a dose, given once in three to four hours has done best; chloroform water alone or combined with a little dilute hydrocyanic acid is very useful. Opium and its derivatives should be avoided entirely, excepting in advanced cases where they are the only remedies that give the patient any relief; of the various anodyne preparations, codeia and chlor-anodyne are the two that I have found most useful.

Dyspnea.-Not a very common symptom in phthisis, is sometimes very troublesome. For its relief, when not dependent upon the cardiac weakness, the fl. ext. quebracho I have found invaluable.

Pain in the chest is best relieved by strapping the chest or, if this fails, by hypodermic injection of morphin.

Hemoptysis.--Morphin hypodermically, rest in th bed, dry cupping of chest, followed for several weeks by the internal use of the infusion of bugle-weed (Lycopus Virginicus).

Fever.--Best controlled by the nuclein administration. Sponging with alcohol and water is often of great value. Regular bathing should be a part of the routine treatment of every case.

Swerting.--This generally disappears during the th treatment with nuclein. Sometimes, however, it requires special treatment. Atropin and aromatic to sulphuric acid still remain at the head of the list of drugs useful in controlling this distressing symptom.

The dyspeptic symptoms require special study in each case and no general rule can be laid down for their treatment. Sometimes recourse to a diet of nothing but koumyss for two or three weeks will give the needed rest to the stomach and later allow a gradual return to a mixed diet. In all cases frequent examinations of the blood should be made in order to determine whether we are gaining on the anemia that is present to a greater or less degree in them all. Red bone marrow is the best agent to combat the anemia.

REMOTE EFFECTS OF BONE TRAUMA.

Read at the Third Annual Meeting of the American Academy of Railway Surgeons, held at Chicago, Ill., Sept. 23, 24 and $25,1896$.

BY D. S. FAIRCHILD, M.D.

SURGEON TO THE CHICAGO AND NORTHWESTERN RAILWAY. ClintoN, IOWA.

Some experiences during the past few years has suggested the subject of this paper, and I have in consequence examined a considerable range of medical literature for the purpose of obtaining data upon which to base certain propositions. The result is somewhat disappointing for the reason that writers, even those standing highest as authorities, have written but little in reference to the remote consequences of bone injury, especially in relation to such cases as may become the subject of controversy. Exception must be marle of the writings of those who before the discovery of the special eanse of tuberculosis regarded certain classes of joint disease and certain cases of osteomyelitis as the result of injury more or less remote, recognized or assumed

The effects of injuries upon the future condition of bone tissue are so varying in their nature that it would be quite impossible to predicate the future possibilities in any case of trauma in an empiric manner based upon experience alone, but rather, in the first place, on well-known pathologic facts. The apparent relation of cause and effect in medicine are, as is well known, so often misleading that a most critical application of facts, derived from a close study of pathology, becomes necessary to protect the surgeon from falling into serious error. So many writers on medical, as well as on other subjects, have fallen into the habit of loose and indefinite statement, that it is not difficult to find that the highest authority may be used in the support of propositions, often no doubt, quite in discordance with the author's real views.

It is true that unusual difficulties lie in the way of certainty in medicine from the fact of the complex nature of the subject and of the unforseen accidents which may arise to complicate the course of events, but much of this may be avoided by the employment of critical methods of study. The primary consideration in the study of the subject of this paper must be the influence of injuries in producing bone inflammation.

It is generally agreed that contusions of bone will produce swelling of the periosteum from extravasation and if the injury is sufficient or of such a character as to influence the bone an osteoplastic process will follow. It may generally be expected that resolution will take place in a short time, and that the periosteum and bone will be restored to to their former condition. If, however, this does not take place other results will follow, which it is the object of this paper to consider, and if we can reach an understanding of what may be expected from the standpoint of pathology and from the most reliable practical observations, we may be able to answer certain questions and come to conclusions which will be just and proper.

Leaving out of consideration for the present moment the results of infection, we will consider the effects of the osteoplastic process when resolution does not take place. I think it proper to stop long enough at this point to say that chronic irritation or inflammation of bone can not continue for an indefinite period of time without certain organic changes taking place. Assuming an injury to be the cause of an inflammation or an irritation of a more or less persistent character, we have as a result a proliferation of cells.

The density of bone tissue is such as to interfere with this multiplication of cells without the occurrence of a coincident absorption of bone substance, hence the bone changes in condition. The vascular structure of bone periosteum and medulla are involved, becoming more vascular and an exudation takes place underneath the periosteum into the medulla and into the enlarged Haversian canals, or in spongy bone into the trabecular structure. As the embryonic cells increase in number the osseous lamella becomes softened and absorbed and the lacunæ become larger, and these with the enlarged Haversian canals become filled with granulation tissue together with multinuclear cells, osteoclasts, which are believed to aid in the absorption of bone. 